\title{
Increased tumor vascularization is associated with the amount of immune competent PD-1 positive cells in testicular germ cell tumors
}

\author{
LUKAS JENNEWEIN $^{1,2 *}$, GEORG BARTSCH ${ }^{3 *}$, KILIAN GUST $^{4}$, HANS-MICHAEL KVASNICKA ${ }^{5,6}$, \\ AXEL HAFERKAMP $^{3}$, ROMAN BLAHETA $^{7}$, MICHEL MITTELBRONN $^{8}$, PATRICK N. HARTER ${ }^{1,6}$ and JENS MANI ${ }^{7}$ \\ ${ }^{1}$ Neurological Institute (Edinger Institute), Goethe University, D-60528 Frankfurt/Main; ${ }^{2}$ Department of Obstetrics and \\ Gynecology, Goethe University, D-60590 Frankfurt/Main; ${ }^{3}$ Department of Urology, Johannes Gutenberg University, \\ D-55131 Mainz, Germany; ${ }^{4}$ Department of Urology, Medical University of Vienna, A-1090 Vienna, Austria; \\ ${ }^{5}$ Senckenberg Institute of Pathology, Goethe University of Frankfurt/Main, D-60590 Frankfurt/Main; \\ ${ }^{6}$ German Cancer Consortium (DKTK) and German Consortium for Translational Cancer Research (DKTK), \\ D-69120 Heidelberg; ${ }^{7}$ Department of Urology, Goethe University, D-60590 Frankfurt/Main, \\ Germany; ${ }^{8}$ Luxembourg Centre of Neuropathology, L-3555 Dudelange, Luxembourg
}

Received October 12, 2017; Accepted January 22, 2018

DOI: $10.3892 / 01.2018 .8597$

\begin{abstract}
Testicular germ cell cancer in a metastatic state is curable with a cisplatin-based first line chemotherapy. However, $10-15 \%$ of these patients are resistant to first line chemotherapy and are thus left with only palliative options. Immunotherapies and inhibition of angiogenesis used in multiple types of cancer; however, the molecular context of angiogenesis and immune checkpoints in the development and progression of testicular cancers is still unknown. Therefore, the present study performed tissue micro array based analysis of 84 patients with immunohistochemistry of programmed cell death protein 1 (PD-1), programmed cell death ligand 1 (PD-L1) and vascular endothelial growth factor receptor 2 (VEGFR2) of testicular cancer and corresponding normal appearing testis tissue, matching the results with clinical data. The results demonstrated that PD-L1 was significantly upregulated in testicular tumors and that PD-1 positive cells significantly infiltrated the testicular tumor when compared with normal testicular tissue. VEGFR2 was significantly upregulated in testicular cancer. It was indicated that PD-1 expressing cytotoxic cells may require pathologic tumor
\end{abstract}

Correspondence to: Dr Jens Mani, Department of Urology, Goethe University, Theodor-Stern-Kai 7, D-60590 Frankfurt/Main, Germany

E-mail: jens.mani@kgu.de

${ }^{*}$ Contributed equally

Key words: programmed cell death protein 1, programmed cell death ligand 1, vascular endothelial growth factor receptor 2, testicular cancer, immune vessels to pass the blood-testis-barrier in order to migrate into the tumor. Notably, when matching the clinical data for PD-1, PD-L1 and VEGFR2 there were no differences in expression in the different International Germ Cell Cancer Collaborative Group stages of non-seminoma. These data suggested that the anti-PD-1/PD-L1 immunotherapy and the anti-angiogenic therapy, sequentially or in combination, may be a promising option in the treatment of testicular cancer.

\section{Introduction}

Testicular germ cell cancer in a metastatic state is curable with a cisplatin-based first line chemotherapy (1). It is assumed that the fast response upon chemotherapy is mediated by apoptosis (2). Notwithstanding $10-15 \%$ of the patients are refractory to first line chemotherapy and are hereby left with palliative options $(3,4)$. The high toxicity of the cisplatin-based first line chemotherapy and the presence of non-responders with potentially lethal clinical courses show the need of alternative treatment strategies. Immunotherapies apply their antitumor effect through mechanisms apart from standard cytotoxic agents. The adaptive immune system has a number of mechanisms to detect and eliminate cells with foreign antigens and has shown to be important for tumor supressive activity. Cancer cells can escape this immune response through active interference with the antigen-antibody recognition system (5). Programmed death receptor ligand 1 (PD-L1) is expressed on various cancers and has been reported to play an important role in mediating and promoting immunosuppression (6). The interaction between PD-L1 and programmed cell death protein 1 (PD-1), which is expressed on immune cells including T-cells attenuates lymphocytes activation and impairs anti-cancer T-cell immune reaction (7). PD-1 and PD-L1 Inhibitors are already used as treatment of different cancers like melanoma, lung cancer, kidney or bladder cancer (8-11). In some cancers 
the level of PD-L1 expression is important for the response of the checkpoint inhibitor $(12,13)$.

An essential hallmark of cancer growth and metastasis is marked pathologic angiogenesis (14). The deficient, hypoxic tumor vasculature can also create an abnormal microenvironment, which alters the proliferation, function and differentiation of immune cells $(15,16)$.

Vascular endothelial growth factor (VEGF) is the most important angiogenic stimulation factor. Vascular endothelial growth factor receptor 2 (VEGFR2) mediates vascular endothelial growth. Several Studies have reported an important role of VEGFR2 expression in the pathogenesis and progression of testicular cancer $(17,18)$.

Still tyrosin kinase inhibitors (TKIs) with VEGFR2 as specific target (sunitinib, carbozantinib) have not been investigated clinically in TGCT patients.

The association between PD-L1 expression and clinical outcomes to vascular endothelial growth-factor targeted therapies have been evaluated in metastatic clear cell renal cell carcinoma (19). The aim of our study was to get first evidence for the potential molecular context of angiogenesis and immune checkpoints in the development and progression of testicular cancers. Therefore, we performed a tissue micro array based analysis with immunohistochemistry of PD-1, PD-L1 and VEGFR2 of testicular cancer and corresponding normal appearing testis tissue.

\section{Materials and methods}

Patient selection and clinico-pathologic analysis. Orchiectomy specimens of 84 testicular cancer patients (41 seminoma patients and 43 non-seminoma patients) from the Goethe University Hospital Frankfurt, Germany from 2002 to 2011 were evaluated. Following histological subtypes were seen: Seminoma, teratocarcinoma, mature teratoma, immature teratoma, embryonal carcinoma, chorion carcinoma, yolk sac carcinoma. All patients provided written informed consent for the use of their tissues, and the study was approved by the ethics committee of the Goethe University, Frankfurt/Main, Germany. All patients revealed adequate clinical follow up data.

The International Germ Cell Cancer Collaborative Group (IGCCCG) defined a prognostic factor-based staging system for metastatic testis tumors based on identification of clinically independent adverse factors. This staging system has been incorporated into the TNM Classification and uses histology, location of the primary tumor, location of metastases and pre-chemotherapy marker levels in serum samples as prognostic factors to categorise patients into 'good', 'intermediate' or 'poor' prognosis [(20,21)EAU]. All patients with metastatic disease were grouped in one of these categories.

Tissue microarray (TMA). All tissue samples were retrieved from orchiectomy specimens, fixed in $10 \%$ buffered formalin and embedded in paraffin at time of surgery. For TMA construction H\&E-stained slides of human testicular germ cell tumors (TGCTs) were reviewed by a certified pathologist. The most representative areas of each tumor sample and assigned corresponding biopsies of the unaffected sites of the orchiectomy specimens were marked. Cores (3 $\mathrm{mm}$ in diameter) were punched out from the chosen areas of the formalin-fixed paraffin-embedded (FFPE) blocks. The samples were assembled in the array. The TMA location number was linked to the database including the clinico-pathologic data.

Immunohistochemistry. An automated immunostainer (Ventana, Strasbourg, France) using standard protocols was used for immunohistochemical stainings. Briefly, $4 \mu \mathrm{m}$ thick slides were heated to $100^{\circ} \mathrm{C}$, incubated with Inhibitor D (Ventana) and then incubated with the primary antibody [PD-L1: Cell Signaling rabbit monoclonal antibody (no. 13684; Cell Signaling Technology, Inc., Leiden, Netherlands); PD-1: Abcam mouse monoclonal antibody (no. ab52587; Abcam Cambridge, UK)]. VEGFR2 (no. 55B11): Cell Signaling rabbit monoclonal antibody (no. 2479S; Cell Signaling Technology, Inc.)]. The secondary antibody solution was incubated after rinsing, followed by sequential incubation with Blocker D (Ventana) and SA-HRP D (Ventana). Visualization was accomplished using DAB D (diaminobenzidine) and DAB $\mathrm{H}_{2} \mathrm{O}_{2} \mathrm{D}$ (Ventana). Finally, the slides were counterstained with Hemalaun and mounted. The detailed immunohistochemical staining procedure was described previously (22).

Staining quality and specificity were assured using established protocols and antibodies (23-30), negative controls prior to staining as well as on-slide positive controls on each tissue micro array slide (Fig. 1). We used tonsil material onevery singletissuemicroarray as a positivecontrolasdescribed in literature before (31-38).

Of note, not every core of the TMA was evaluable for each protein due to technical reasons, resulting in variations of numbers of the analyzed tissue specimens. This fact can be considered a possible limitation of the study.

Scoring. The stained TMAs were evaluated with an Olympus BX50 light microscope. For semi-quantitative evaluation of PD-L1 immunohistochemistry, a multi-score of staining frequency and intensity was applied. Staining frequency was assessed as follows: $0,0-1 \% ; 1,1-10 \% ; 2,10-25 \% ; 3,25-50 \%$; and $4,>50 \%$. The staining intensity was rated as follows: 0 , no staining; 1 , weak; 2 , moderate; and 3, strong. This scoring system was described previously (39). PD-1 immunohistochemistry tissue micro array cores were evaluated if PD-1 positive infiltrating cells were present in the tumor $(=1)$ or not $(=0)$. VEGFR2 expression was categorized into the following expression intensities: 0 , no staining; 1 , weak; 2 , moderate; and 3 , strong.

Statistical analysis. The semi-quantitative scores were assigned as ordinal scale response variable and analyzed together with nominal variables (tissue/tumor type). Non-parametric Wilcoxon test was used for statistical analyses regarding histology scores. Chi-square test was performed analyzing contingency tables. Significance level of $\alpha=0.05$ was selected for all tests. Statistical analysis was performed using JMP 11.0.0 software (SAS Institute, Inc., Cary, NC, USA).

\section{Results}

PD-L1 is significantly upregulated in testicular tumor and PD-1 positive cells significantly infiltrate the testicular tumor 
compared to normal testicular tissue. We did not detect PD-1 expression on cells morphologically identifiable as tumor cells in any of the tumor samples or in the normal testicular tissue (Fig. 2A-C).

Of note, the PD-1 positive infiltrating cells both in seminoma (Fig. 2B) and non-seminoma (Fig. 2C) show a higher count than in normal testicular tissue. Here we could not detect PD-1 positive infiltrates (Fig. 2A).

Immunohistochemical analyses for PD-L1 revealed that the checkpoint protein was mainly detected within the parenchyma of the tumor of seminomas (Fig. 2E) and non-seminomas (Fig. 1F) in comparison to the normal tissue (Fig. 2D).

These findings were confirmed by statistical analysis. We found general significant differences in PD-L1-expression between normal tissue vs. tumor (Fig. 3B) with $\mathrm{P}<0.0001$ and also in PD-1 positive infiltrative cells in the neoplastic testis (Fig. 3A) with $\mathrm{P}=0.018$. Seminoma and non-seminoma both show on separate analysis to the normal tissue significant expression of PD-L1 (Fig. 4C and D) and significant amount of PD-1 positive infiltrating cells (Fig. 4A and B).

On comparison of seminoma vs. non seminoma there is no significant difference of infiltration of PD-1 positive infiltrating cells (Fig. 5A) and PD-L1 expression (Fig. 5B).

VEGFR2 is significantly upregulated in testicular tumor. In general, staining scores were significantly higher for VEGFR2 in the tumor tissue (Fig. 3C) in comparison to the normal testis $(\mathrm{P}=0.002)$. Here we see a distinct loco-regional pattern with higher scores in areas with a higher vessel density. But on a separate immunohistochemical analysis only non-seminoma (Fig. 2I) show a higher expression in comparison to normal tissue (Fig. 3G) with $\mathrm{P}=0.02$ (Fig. 4F). VEGFR2 expression in seminoma (Fig. 2H) compared to normal tissue is not significantly different (Fig. 4E). Whereas non-seminoma has a significantly higher expression of VEGFR2 compared to seminoma (Fig. 5C).

PD-1, PD-L1 and VEGFR2 show no difference in expression in IGCCCG stages of non-seminoma. The IGCCCG defines a prognostic factor-based staging system for metastatic testis tumour based on identification of some clinical independent adverse factors (EAU).

In our analysis only non-seminoma patients with known IGCCG stage were included. Here we have patient distribution in all 3 stages (good, intermediate and poor). When comparing the level of tumor expression of PD-L1 (Fig. 6A) and VEGFR2 (Fig. 6B) and the PD-1 positive infiltrate cells (Fig. 6C) in regards of these three clinical stages there is no significant difference, respectively.

In IGCCCG of seminoma there is only good and intermediate prognosis per se. But in our case we have only seminoma patients with known IGCCG good prognosis. Thus no further statistical evaluation was possible.

\section{Discussion}

In our study we investigated the expression profiles of PD-L1, PD-1 and VEGFR2 in different types of testicular cancer and normal appearing testis tissue to gain a first insight into

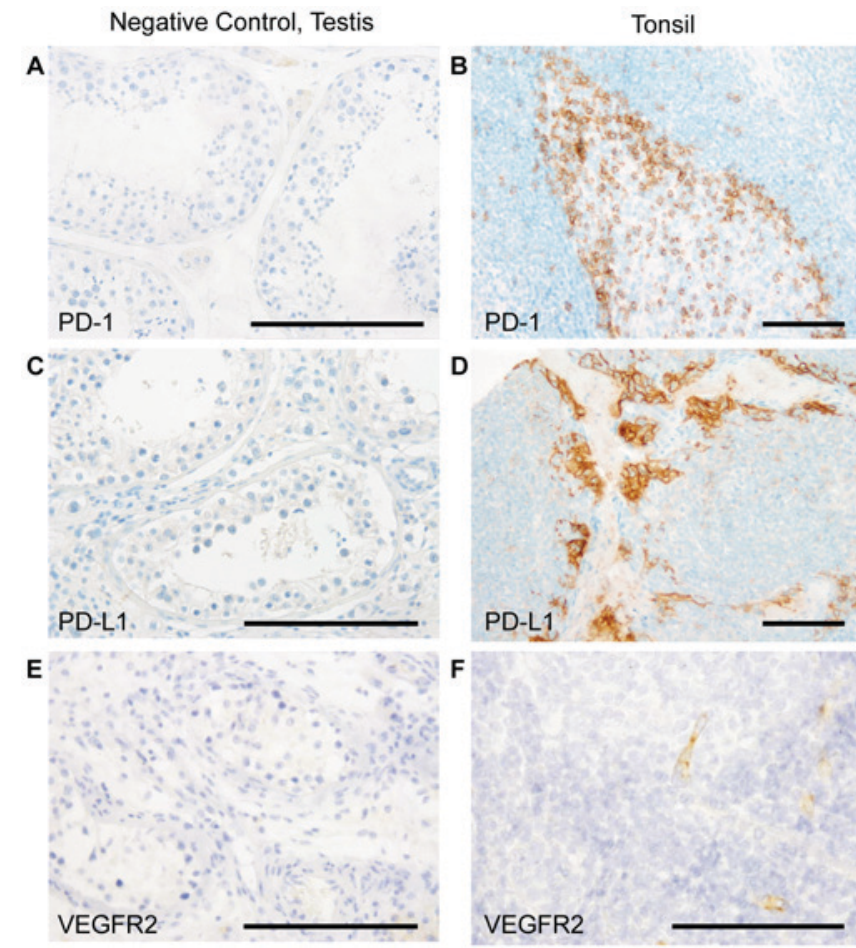

Figure 1. Assurance of staining quality and specificity. (A) PD1-immunohistochemistry of normal appearing testicular tissue without primary antibody as a negative control. (B) PD1-immunohistochemistry of a tonsil as a positive control. Tonsil material was on every single tissue micro array as a positive control. (C) PD-L1-immunohistochemistry of normal appearing testicular tissue without primary antibody as a negative control. (D) PD-L1-immunohistochemistry of a tonsil as a positive control. Tonsil material was on every single tissue micro array as a positive control. (E) VEGFR2-immunohistochemistry of normal appearing testicular tissue without primary antibody as a negative control. (F) VEGFR2-immunohistochemistry of a tonsil as a positive control showing positive endothelial staining. Tonsil material was on every single tissue micro array as a positive control. Scale bars $=100 \mu \mathrm{m}$. PD-1, programmed cell death protein 1; PD-L1, programmed cell death ligand 1; VEGFR2, vascular endothelial growth factor receptor 2 .

a potential in vivo correlation of tumor immune-checkpoint status and angiogenesis.

In the last decade multiple approaches were undertaken in order to team up with the immune system in the fight against cancer. Excitement was great upon the introduction of e.g., vaccines or monoclonal antibodies.

In a great number of recent studies immune checkpoint inhibitors seem to be promising options in urogenital malignancies in different therapeutic settings and stages $(8,9,40)$. Immune checkpoints like PD-L1 are pivotal to prevent autoimmunity. Through a complex system of excitatory and inhibitory signals, circulating PD-1-receptor carrying immune cells, like activated CD4+ T cells, CD8+ T cells, natural killer cells, monocytes and B cells, can be activated or inhibited (41). With this mechanism malignant cells can be immunologically identified. But multiple tumors express immune checkpoints to escape lethal immune cell attacks. From an immunologic point of view it is known that the testis tissue has a naturally suppressed immune response (42) and is considered a privileged site (43). It can tolerate autoantigens from developing germ cells. The immunologic homeostasis involves multiple mechanisms such as physiological anatomical structure, 

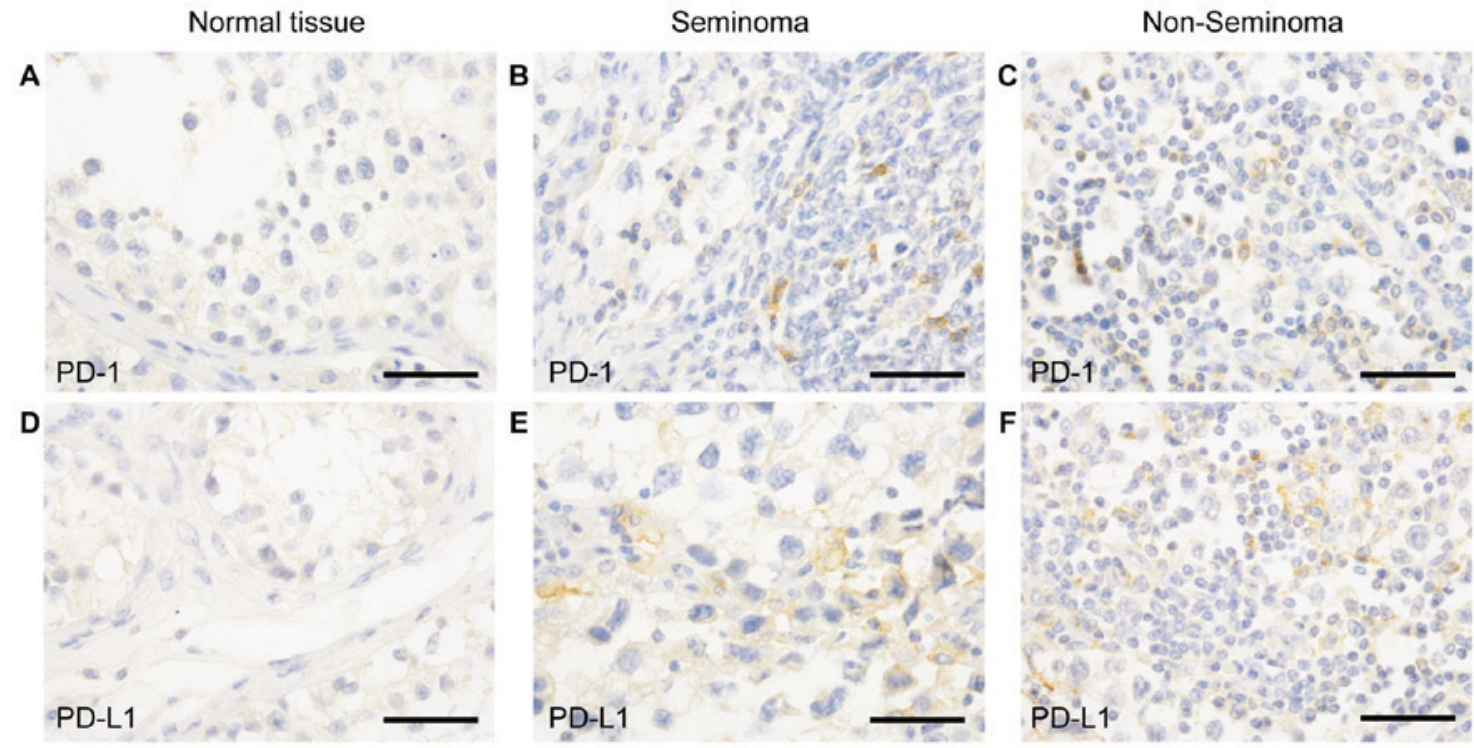

G
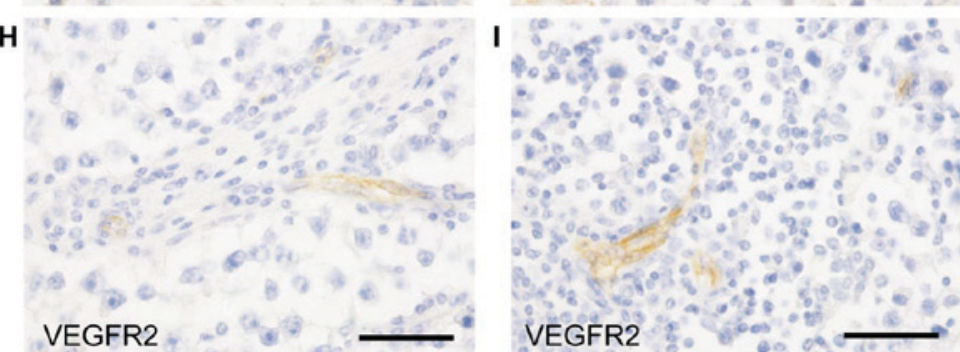

Figure 2. Immunohistochemistry of PD-1, PD-L1 and VEGFR2 in human testicular cancer. (A) PD-1-immunohistochemistry of normal appearing testicular tissue. (B) PD-1-immunohistochemistry of a classical seminoma. (C) PD-1-immunohistochemistry of an embryonal testicular carcinoma. (D) PD-L1-immunohistochemistry of normal appearing testicular tissue. (E) PD-L1-immunohistochemistry of a classical seminoma. (F) PD-L1-immunohistochemistry of an embryonal testicular carcinoma. (G) VEGFR2-immunohistochemistry of normal appearing testicular tissue. (H) VEGFR2-immunohistochemistry of a classical seminoma. (I) VEGFR2-immunohistochemistry of an embryonal testicular carcinoma. Scale bars=50 $\mu \mathrm{m}$. PD-1, programmed cell death protein 1; PD-L1, programmed cell death ligand 1; VEGFR2, vascular endothelial growth factor receptor 2.
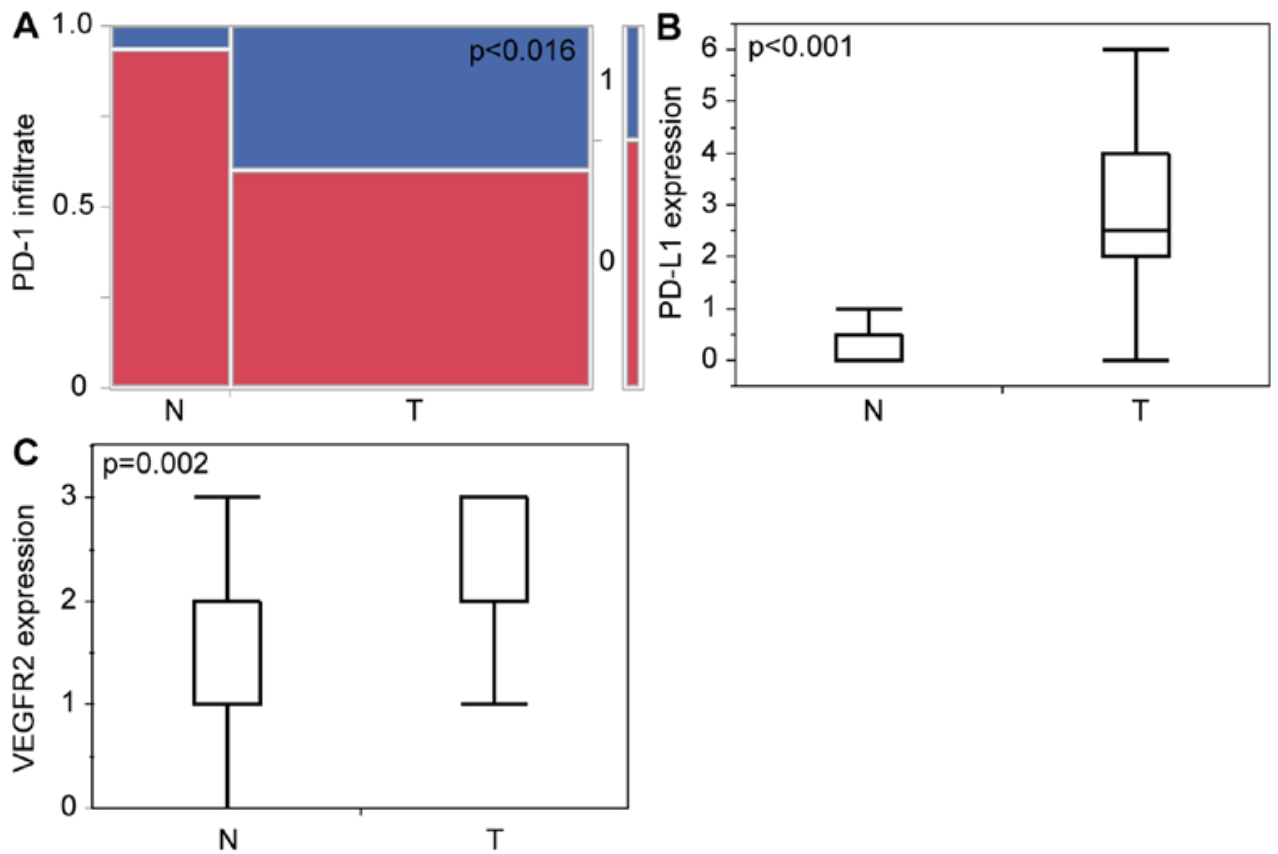

Figure 3. Statistical analysis of immunohistochemical staining of tumor vs. normal tissues. (A) Contingency table of the presence of PD-1-immunopositive infiltrating cells $(0=$ no, $1=y e s)$ of normal appearing testicular tissue $(n=15 ;$ no, 14/93.3\%; yes, $1 / 6.67 \%)$ and testicular cancer $(n=45 ;$ no, 27/60\%; yes, 18/40\%) $\mathrm{P}=0.0162$. (B) Histogram of PD-L1 expression score of normal appearing testicular tissue ( $\mathrm{n}=17$; min: 0 ; max: 3 ; mean: 0$)$ and testicular cancer ( $=46$; min, 0 ; max, 6; mean, 2.5), $\mathrm{P}<0.001$. (C) Histogram of VEGFR2 expression score of normal appearing testicular tissue ( $\mathrm{n}=14$; min, 0 ; max, 3; mean, 1) and testicular cancer ( $\mathrm{n}=67$; min, 0; max, 3; mean, 2), $\mathrm{P}=0.002$. PD-1, programmed cell death protein 1; PD-L1, programmed cell death ligand 1; VEGFR2, vascular endothelial growth factor receptor 2 ; N, normal testicular tissues; $\mathrm{T}$, testicular cancer tissues. 

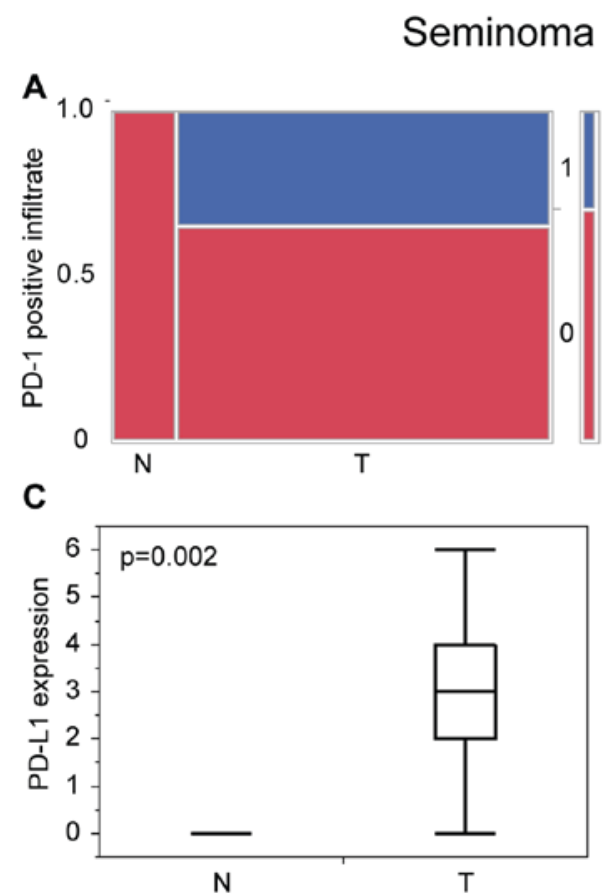

E
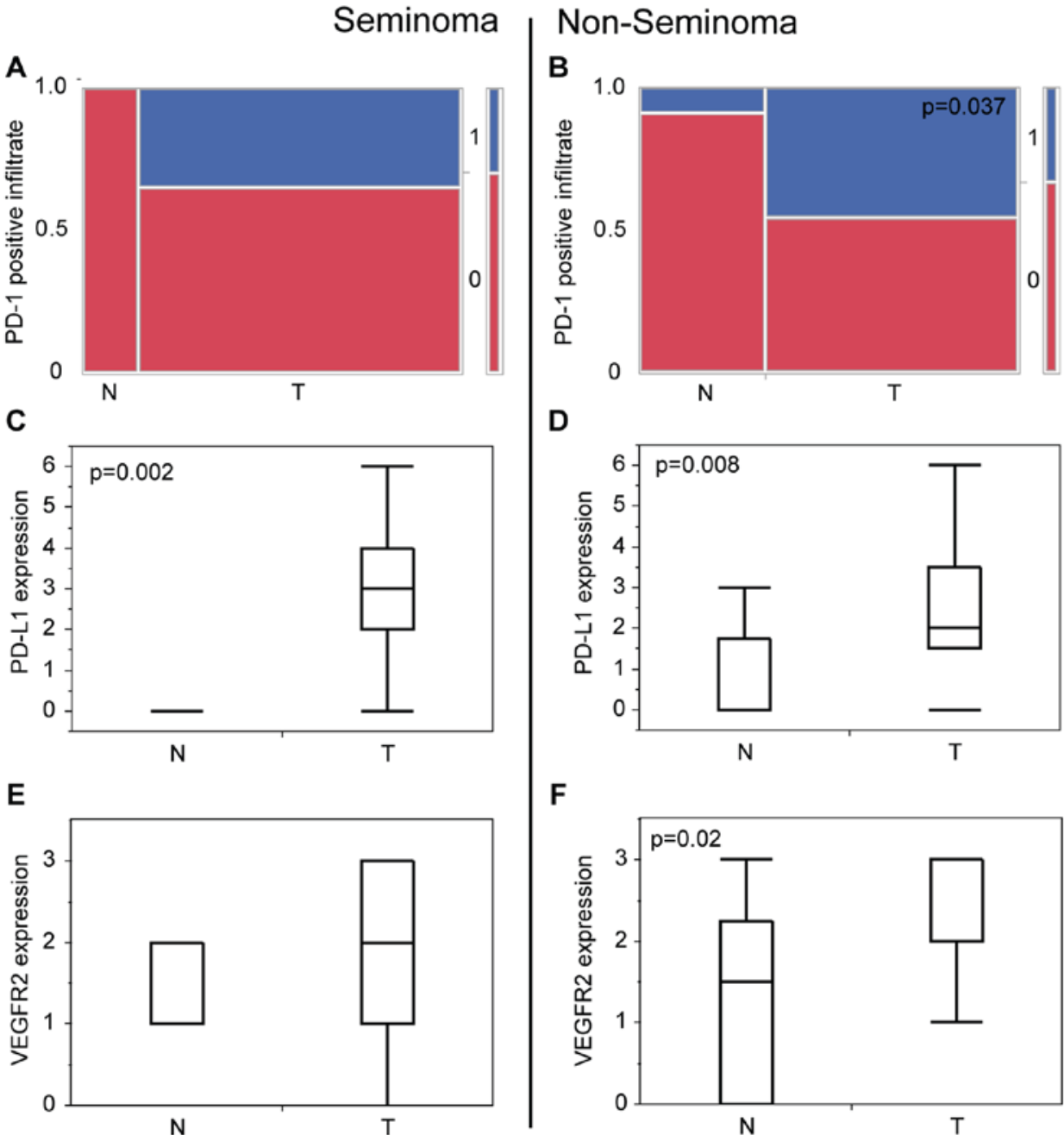

D
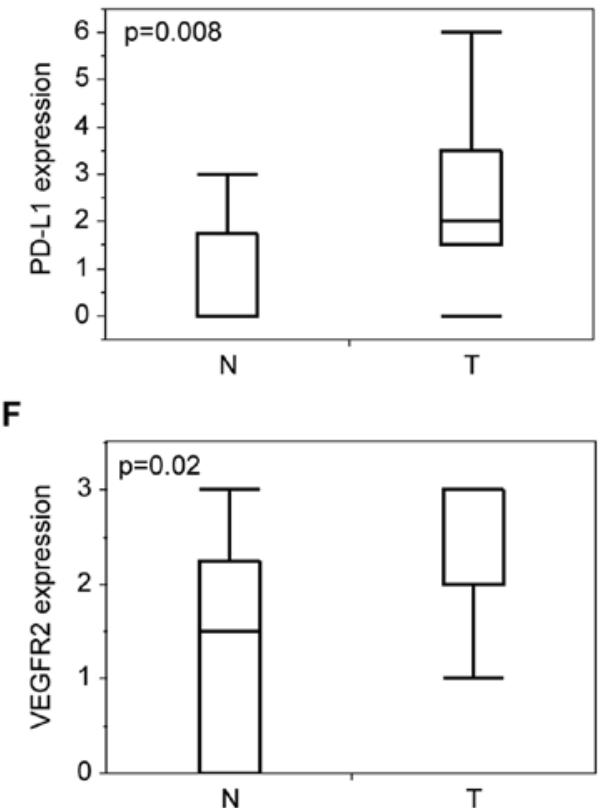

Figure 4. Statistical analysis of immunohistochemical staining of tumor vs. normal tissues grouped in Seminoma and Non-Seminoma. (A) Contingency table of the presence of PD-1-immunopositive infiltrating cells $(0=$ no, $1=$ yes) in seminoma of normal appearing testicular tissue $(\mathrm{n}=4$; no, $4 / 100 \%$; yes, $/ 0 \%)$ and testicular cancer ( $\mathrm{n}=23$; no, 15/65.2\%; yes, $8 / 34.8 \%$ ) $\mathrm{P}=0.160$. (B) Contingency table of the presence of PD-1-immunopositive infiltrating cells $(0$, no; 1 , yes) in non-seminoma of normal appearing testicular tissue ( $\mathrm{n}=11$; no, 10/90.9\%; yes, $1 / 9.1 \%)$ and testicular cancer $(\mathrm{n}=22$; no, 12/54.5\%; yes, 10/45.5\%) $\mathrm{P}=0.037$. (C) Histogram of the PD-L1 expression score of normal appearing testicular tissue of patients with seminomas ( $\mathrm{n}=9$; min: 0 ; max: 1; mean: 0) and seminoma tissue ( $\mathrm{n}=25$; min, 0; max, 6; mean, 3), $\mathrm{P}=0.002$. (D) Histogram of the PD-L1 expression score of normal appearing testicular tissue of patients with non-seminomas ( $\mathrm{n}=8$; min, 0 ; max, 3; mean, 0) and non-seminoma tissue ( $\mathrm{n}=21$, min, 0; max, 6; mean, 2), $\mathrm{P}=0.008$. (E) Histogram of the PD-1 expression score of normal appearing testicular tissue of patients with seminomas $(\mathrm{n}=8 ; \min , 1 ; \max , 2 ;$ mean, 1$)$ and seminoma tissue $(\mathrm{n}=35 ; \min , 0$; max, 3; mean, 2), $\mathrm{P}=0.051$. (F) Histogram of the PD-1 expression score of normal appearing testicular tissue of patients with non-seminomas $(\mathrm{n}=6 ; \min , 0 ;$ max, 3; mean, 1.5) and non-seminoma tissue ( $\mathrm{n}=32$; min, 1; max, 3; mean, 3), $\mathrm{P}=0.002$. PD-1, programmed cell death protein 1; PD-L1, programmed cell death ligand 1; VEGFR2, vascular endothelial growth factor receptor $2 ; \mathrm{N}$, normal testicular tissues; $\mathrm{T}$, testicular cancer tissues.

systemic immune tolerance, and active local immunosuppression $(44,45)$. Cheng et al discuss that PD-1/PD-L1 contribute to the immune response of the testis (42), which is conflicting to the findings of multiple studies $(25,46)$ including ours with little or no PD-L1 expression in normal testicular tissue as mentioned above.

In our study we see that PD-L1 is significantly upregulated in testicular cancer in comparison to the normal tissue. The phenomenon of elevated PD-L1 expression in testicular germ cell cancer has been described before $(25,46)$. Contrary to the findings of Cierna et al (25) we see no significant difference in the PD-L1 expression of seminoma and non-seminoma.

The percentage values of Fankhauser et al may also imply a not statistical difference of PD-L1 expression between seminoma and non-seminomatous tumors (46).
The comparison of seminoma and non-seminomatous (Non-seminomatous germ cell tumors, NSGCT) tumors is complicated. The NSGCTs are a very heterogeneous group containing chorioncarcinoma, yolk sac tumors, embryonal carcinoma and teratoma. Separate positive PD-L1 expression analysis showed values between $13 \%$ (teratoma) and $80 \%$ (chorioncarcinoma) (46).

In general the direct comparison of studies is especially difficult because of inconsistent scoring and divergent used antibodies.

Studies of other genitourinary cancers have shown that the PD-L1 expression status may correlate with the therapeutic response and outcome of PD-L1 and PD-1 immunotherapy (47). This may also be the case in testicular cancer. But as mentioned above a standardized scoring system is needed in order to answer this question. 

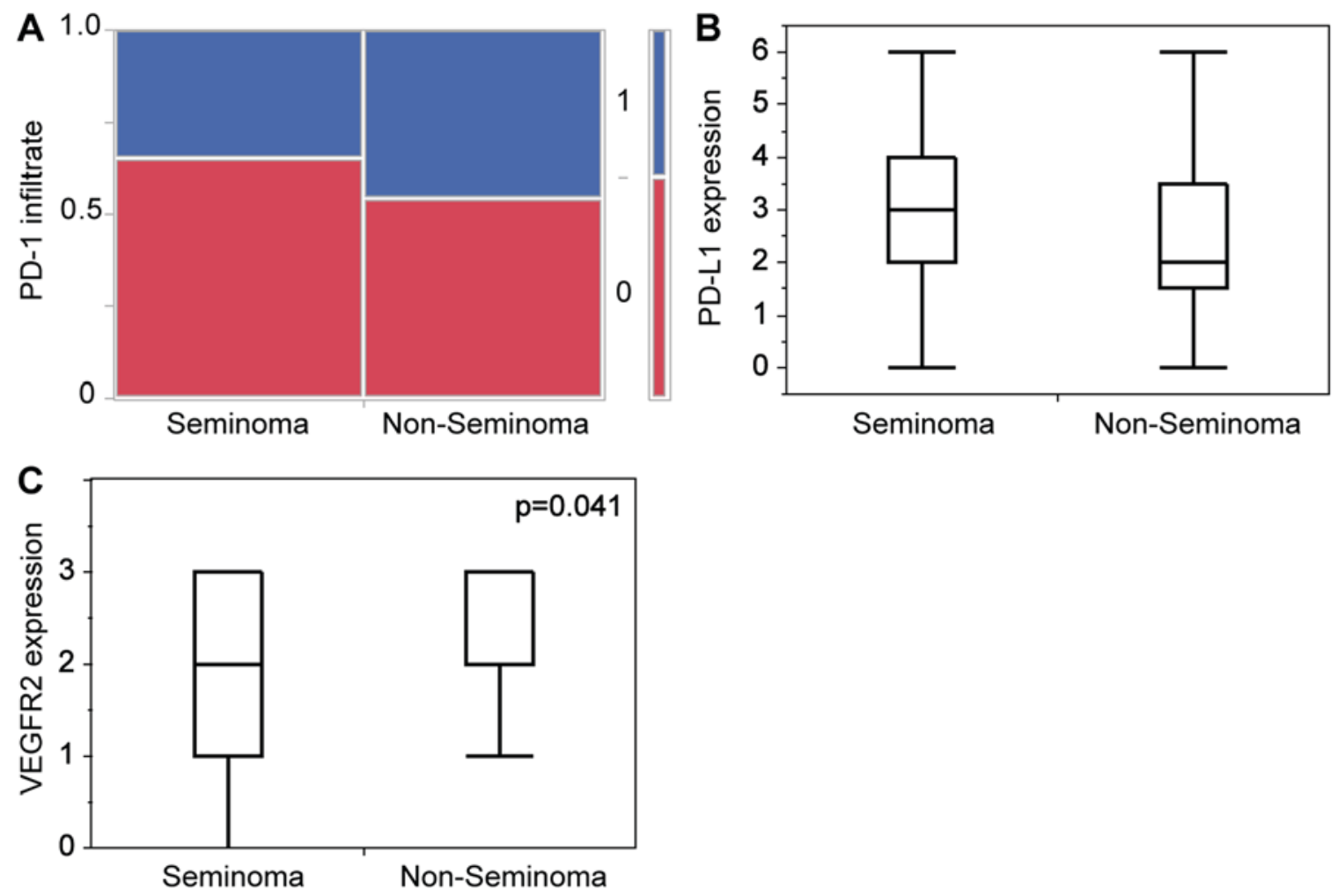

Figure 5. Statistical analysis of immunohistochemical staining of Seminoma vs. Non-Seminoma. (A) Contingency table of the presence of PD-1-immunopositive infiltrating cells $(0$, no; 1 , yes) of seminoma ( $\mathrm{n}=23$; no, $15 / 65.2 \%$; yes, $8 / 34.8 \%$ ) and non-seminoma ( $\mathrm{n}=22 ;$ no, $12 / 54.5 \%$; yes, 10/45.5\%) $\mathrm{P}=0.465$. (B) Histogram of the PD-L1 expression score of seminomas ( $\mathrm{n}=25$; min, 0 ; max, 6 ; mean, 3 ) and non-seminomas $(\mathrm{n}=21 ; \min , 0 ;$ max, 6 ; mean, 2), $\mathrm{P}=0.507$. (C) Histogram of the VEGFR2 expression score of seminomas ( $\mathrm{n}=35$; min, 0 ; max, 3 ; mean, 2 ) and non-seminomas ( $\mathrm{n}=32$; min: 1 ; max: 3 ; mean: 3), P=0.041. PD-1, programmed cell death protein 1; PD-L1, programmed cell death ligand 1; VEGFR2, vascular endothelial growth factor receptor 2.

Another important pillar of the physiologic immune (suppressing) testicular system is the Blood-Testis-Barrier (BTB). The BTB can provide an adequate microenvironment for spermatogenesis, by effectively preventing immunological component in the blood from entering the seminiferous tubules and by sequestering the autoantigenic germ cell from access to the immune system (44). In case of malignant lesions this barrier will be destroyed. Pathologic vessels run through the neoplasm.

Previous studies suggested that VEGF and its receptors VEGFR have an important role in the development and progression of TCGT (48). Adam et al described increased expression of VEGF and VEGFR2 in patients with TGCT especially in non-seminoma (49). Nitzsche et al showed that blocking VEGFR2 with the antiangiogenic compound HP-14 inhibited growth of platinum sensible and -resistant TGCT cells and suppressed tumor angiogenesis (18).

In line with these results sunitinib, an orally applicable VEGFR2 inhibitor has been evaluated in a phase II study in platinum refractory advanced germ cell tumor patients (50). We also see that VEGFR2 is significantly upregulated in testicular tumor as compared to normal tissue. But in the separate tumor analysis VEGFR2 shows a higher expression in non-seminoma tumor than in seminoma. Jones et al have shown that non-seminomatous tumours have a higher microvesicular density and higher expression of VEGF (51). Nevertheless it is known that seminomatous tumors, with their homogeneous sections, are crisscrossed with tiny unnatural venule like tumor vessels (52).
Our findings imply that immune cells are able to infiltrate the usually immune-privileged testicular tissue because of the vascular structural alteration resulting from malignant transformation. The damaged BTB cannot maintain the immune suppressive environment.

We see a significant infiltration of PD-1 positive immune cells in both subtypes of testicular tumor compared to normal tissue with no significant difference between the two types of tumor. The presence of PD-1 presenting tumor infiltrating lymphocytes (TILs) may have strong prognostic and predictive features in different types of tumors (53-56). Contrary to our findings, a recent study showed more PD-1 expressing TILs in seminoma (87\%) vs. non-seminoma $(42,9 \%)$ in direct comparison (6). In the case of seminoma a study of Sakai et al described TIL recruitment into tumor tissue through aforementioned tiny venule like tumor vessels (52). Chovanec et al stated that PD-1 expressing TILs did neither have prognostic value nor a correlation with clinico-pathologic characteristics (24). Interestingly, same has been shown in brain metastases, which also grow in an immune-privileged micromillieu (23).

We also see no significant difference in PD-1 expressing TILs in the different clinical IGCCCCG stages (Fig. 6A, B).

A major limitation of the study is the retrospective nature and the absence of extragonadal tumor or metastatic tumor tissue, which behavior during treatment finally defines the success of therapy and the clinical result. Despite of these facts the findings of the study should be regarded as hypothesis generating. 


\section{Non-Seminoma}
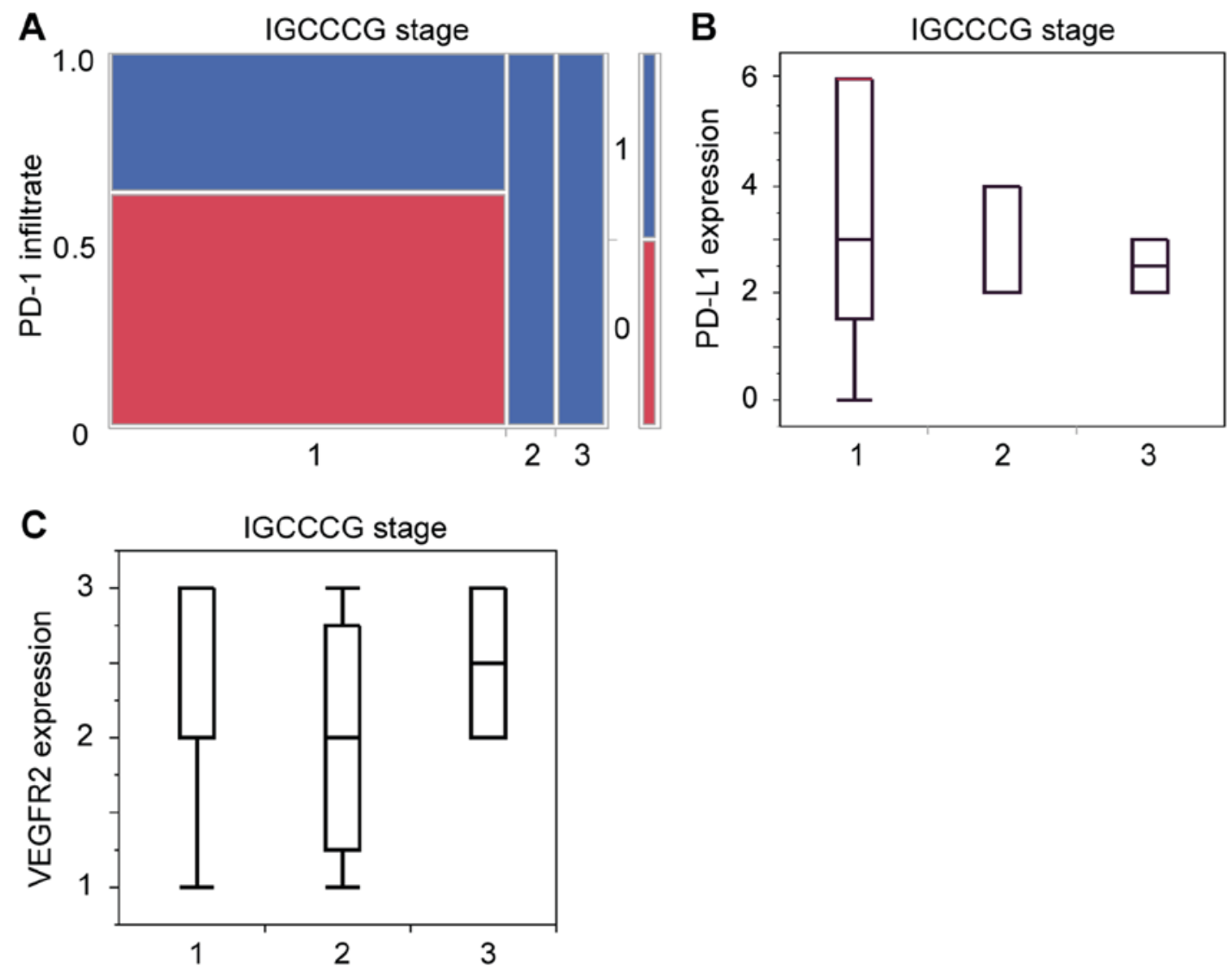

Figure 6. Statistical analysis of immunohistochemical staining of the biomarkers in dependence of IGCCCG stage. (A) Contingency table of the presence of PD-1-immunopositive infiltrating cells $(0=$ no, $1=$ yes) in the non-seminoma of different IGCCCG stages (stage 1 : n=16; no, 10/62.5\%; yes, 6/37.5\%; stage 2: n=2; no, 0/0\%; yes, 2/100\%; stage 3: n=2; no, 0/0\%; yes, 2/100\%) P=0.82. (B) Histogram of the PD-L1 expression score of IGCCCG good prognosis (stage 1: $\mathrm{n}=13$; min, 0 ; $\max , 6$; mean, 3), IGCCCG intermediate prognosis (stage 2: $\mathrm{n}=3$; min, 2; max, 4; mean, 2) and IGCCCG poor prognosis (stage 3: $\mathrm{n}=2$; min, 2; max, 3; mean, 2.5) P=0.968. (C) Histogram of VEGFR2 expression score of IGCCCG good prognosis (1: n=22, min: 1; max: 3; mean: 3), IGCCCG intermediate prognosis (stage 2: $\mathrm{n}=4$; min, 1 ; max, 3; mean, 2) and IGCCCG poor prognosis (stage 3: $\mathrm{n}=2$; min, 2; max, 3; mean, 2.5) P=0.248. IGCCCG, International Germ Cell Cancer Collaborative Group; PD-1, programmed cell death protein 1; PD-L1, programmed cell death ligand 1; VEGFR2, vascular endothelial growth factor receptor 2 .

Our investigation shows the presence of potential PD-1 expressing cytotoxic immune cells in the tumor microenvironment, hypothetically migrated through a pathologic vascular system with an impaired BTB. The morbid tumor vascularity usually creates a more immune suppressive microenvironment in different types of cancer (57-59). But in testicular cancer, with an already physiologic suppressed immunologic microenvironment, there is a paradox effect with an influx of immune competent cells.

However these cells cannot exert their antitumor and cytotoxic effects because they are exposed to inhibition through the PD-L1 immune escape of the tumor. Neither of these loco-regional molecular findings of VEGFR2 expression, PD-L1 expression nor PD-1 expressing TILs seem to correlate with clinico-pathologic characteristics in our patient cohort (Fig. 6A-C).

Our data suggests that both the anti- PD-1/ PD-L1 immunotherapy and the anti-angiogenic therapy might be a promising option in the treatment of testicular cancer. It needs to be addressed, after further evaluation of PD-1, PDL-1 and VEGFR2 function in testicular cancer, whether these treatment options could be possibly administered individually, sequentially or in combination. In this matter evaluation of the effect of knocking down or elevating the expression of PD-1 on vascularization e.g., in an animal model would be decisive.

It seems feasible that PD-1 expressing cytotoxic cells need tumor vessels in order to migrate into the tumor. Here an anti-angiogenic treatment might obstruct the path into the tumor for the immune competent cells and thus diminish the effect of the PD-L1/PD-1 inhibition. But an alternative hypothesis states that anti-angiogenic agents can also transiently 'normalize' the abnormal structure and function of tumor vasculature to make it more efficient for oxygen and (Anti-PD-L1/PD-1) drug delivery.

Clinical efficiency of the mentioned treatment modalities and the importance of PD-L1- expression and /or PD-1 expressing TILs need further investigation in clinical trials.

\section{Acknowledgements}

MM would like to thank the Luxembourg National Research Fond (FNR) for the support (FNR PEARL P16/BM/11192868 grant). 


\section{References}

1. Hanna NH and Einhorn LH: Testicular cancer-discoveries and updates. N Engl J Med 371: 2005-2016, 2014.

2. Mayer F, Stoop H, Scheffer GL, Scheper R, Oosterhuis JW, Looijenga LH and Bokemeyer C: Molecular determinants of treatment response in human germ cell tumors. Clin Cancer Res 9: 767-773, 2003.

3. Hussain SA, Ma YT, Palmer DH, Hutton P and Cullen MH: Biology of testicular germ cell tumors. Expert Rev Anticancer Ther 8: 1659-1673, 2008 .

4. Oechsle K, Honecker F, Cheng T, Mayer F, Czaykowski P, Winquist E, Wood L, Fenner M, Glaesener S, Hartmann JT, et al: Preclinical and clinical activity of sunitinib in patients with cisplatin-refractory or multiply relapsed germ cell tumors: A canadian urologic oncology group/german testicular cancer study group cooperative study. Ann Oncol 22: 2654-2660, 2011.

5. Farkona S, Diamandis EP and Blasutig IM: Cancer immunotherapy: The beginning of the end of cancer? BMC Med 14: 73, 2016

6. Sui X, Ma J, Han W, Wang X, Fang Y, Li D, Pan H and Zhang L: The anticancer immune response of anti-PD-1/PD-L1 and the genetic determinants of response to anti-PD-1/PD-L1 antibodies in cancer patients. Oncotarget 6: 19393-19404, 2015.

7. Shi L, Chen S, Yang L and Li Y: The role of PD-1 and PD-L1 in T-cell immune suppression in patients with hematological malignancies. J Hematol Oncol 6: 74, 2013.

8. Escudier B, Motzer RJ, Sharma P, Wagstaff J, Plimack ER, Hammers HJ, Donskov F, Gurney H, Sosman JA, Zalewski PG, et al: Treatment beyond progression in patients with advanced renal cell carcinoma treated with nivolumab in checkmate 025. Eur Urol 72: 368-376, 2017.

9. Mehta K, Patel K and Parikh RA: Immunotherapy in genitourinary malignancies. J Hematol Oncol 10: 95, 2017.

10. Gettinger SN, Horn L, Gandhi L, Spigel DR, Antonia SJ, Rizvi NA, Powderly JD, Heist RS, Carvajal RD, Jackman DM, et al: Overall survival and long-term safety of nivolumab (anti-programmed death 1 antibody, BMS-936558, ONO-4538) in patients with previously treated advanced non-small-cell lung cancer. J Clin Oncol 33: 2004-2012, 2015.

11. Weber JS, Gibney G, Sullivan RJ, Sosman JA, Slingluff CL Jr, Lawrence DP, Logan TF, Schuchter LM, Nair S, Fecher L, et al: Sequential administration of nivolumab and ipilimumab with a planned switch in patients with advanced melanoma (CheckMate 064): An open-label, randomised, phase 2 trial. Lancet Oncol 17: 943-955, 2016

12. Patel SP and Kurzrock R: PD-L1 expression as a predictive biomarker in cancer immunotherapy. Mol Cancer Ther 14: 847-856, 2015.

13. Meng X, Huang Z, Teng F, Xing L and Yu J: Predictive biomarkers in PD-1/PD-L1 checkpoint blockade immunotherapy. Cancer Treat Rev 41: 868-876, 2015.

14. Rouhi P, Lee SL, Cao Z, Hedlund EM, Jensen LD and Cao Y: Pathological angiogenesis facilitates tumor cell dissemination and metastasis. Cell Cycle 9: 913-917, 2010

15. Huang Y, Yuan J, Righi E, Kamoun WS, Ancukiewicz M, Nezivar J, Santosuosso M, Martin JD, Martin MR, Vianello F, et al: Vascular normalizing doses of antiangiogenic treatment reprogram the immunosuppressive tumor microenvironment and enhance immunotherapy. Proc Natl Acad Sci USA 109: 17561-17566, 2012

16. Schmid MC and Varner JA: Myeloid cells in the tumor microenvironment: Modulation of tumor angiogenesis and tumor inflammation. J Oncol 2010: 201026, 2010.

17. Nitzsche B, Gloesenkamp C, Schrader M, Hoffmann B, Zengerling $F$, Balabanov $S$, Honecker $F$ and Höpfner $M$ : Anti-tumour activity of two novel compounds in cisplatin-resistant testicular germ cell cancer. Br J Cancer 107: 1853-1863, 2012.

18. Nitzsche B, Gloesenkamp C, Schrader M, Ocker M, Preissner R, Lein M, Zakrzewicz A, Hoffmann B and Höpfner M: Nove compounds with antiangiogenic and antiproliferative potency for growth control of testicular germ cell tumours. Br J Cancer 103: $18-28,2010$.

19. Einstein DJ and McDermott DF: Combined blockade of vascular endothelial growth factor and programmed death 1 pathways in advanced kidney cancer. Clin Adv Hematol Oncol 15: 478-488, 2017.
20. International germ cell consensus classification: A prognostic factor-based staging system for metastatic germ cell cancers. International germ cell cancer collaborative group. J Clin Oncol 15: 594-603, 1997.

21. Albers P, Albrecht W, Algaba F, Bokemeyer C, Cohn-Cedermark G, Fizazi K, Horwich A, Laguna MP, Nicolai $\mathrm{N}$ and Oldenburg J: EAU Guidelines Testicular Cancer. European Association of Urology, 2015. https://uroweb.org/wp-content/ uploads/EAU-Guidelines-Testicular-Cancer-2016-1.pdf.

22. Baumgarten $P$, Harter PN, Tönjes M, Capper D, Blank AE, SahmF von Deimling A, Kolluru V, Schwamb B, Rabenhorst U, et al: Loss of FUBP1 expression in gliomas predicts FUBP1 mutation and is associated with oligodendroglial differentiation, IDH1 mutation and $1 \mathrm{p} / 19 \mathrm{q}$ loss of heterozygosity. Neuropathol App Neurobiol 40: 205-216, 2014

23. Harter PN, Bernatz S, Scholz A, Zeiner PS, Zinke J, Kiyose M, Blasel S, Beschorner R, Senft C, Bender B, et al: Distribution and prognostic relevance of tumor-infiltrating lymphocytes (TILs) and PD-1/PD-L1 immune checkpoints in human brain metastases. Oncotarget 6: 40836-40849, 2015.

24. Chovanec M, Cierna Z, Miskovska V, Machalekova K, Svetlovska D, Kalavska K, Rejlekova K, Spanik S, Kajo K, Babal P, et al: Prognostic role of programmed-death ligand 1 (PD-L1) expressing tumor infiltrating lymphocytes in testicular germ cell tumors. Oncotarget 8: 21794-21805, 2017.

25. Cierna Z, Mego M, Miskovska V, Machalekova K, Chovanec M, Svetlovska D, Hainova K, Rejlekova K, Macak D, Spanik S, et al: Prognostic value of programmed-death-1 receptor (PD-1) and its ligand 1 (PD-L1) in testicular germ cell tumors. Ann Oncol 27: 300-305, 2016.

26. Inaguma S, Wang Z, Lasota J, Sarlomo-Rikala M, McCue PA, Ikeda $\mathrm{H}$ and Miettinen $\mathrm{M}$ : Comprehensive immunohistochemical study of programmed cell death ligand 1 (PD-L1): Analysis in 5536 cases revealed consistent expression in trophoblastic tumors. Am J Surg Pathol 40: 1133-1142, 2016.

27. Mansfield AS, Aubry MC, Moser JC, Harrington SM, Dronca RS, Park SS and Dong H: Temporal and spatial discordance of programmed cell death-ligand 1 expression and lymphocyte tumor infiltration between paired primary lesions and brain metastases in lung cancer. Ann Oncol 27: 1953-1958, 2016.

28. Li CW, Lim SO, Xia W, Lee HH, Chan LC, Kuo CW, Khoo KH, Chang SS, Cha JH, Kim T, et al: Glycosylation and stabilization of programmed death ligand-1 suppresses T-cell activity. Nat Commun 7: 12632, 2016.

29. Miettinen M, Rikala MS, Rys J, Lasota J and Wang ZF: Vascular endothelial growth factor receptor 2 as a marker for malignant vascular tumors and mesothelioma: An immunohistochemical study of 262 vascular endothelial and 1640 nonvascular tumors. Am J Surg Pathol 36: 629-639, 2012.

30. Holzer TR, Fulford AD, Nedderman DM, Umberger TS, Hozak RR, Joshi A, Melemed SA, Benjamin LE, Plowman GD, Schade AE, et al: Tumor cell expression of vascular endothelial growth factor receptor 2 is an adverse prognostic factor in patients with squamous cell carcinoma of the lung. PLoS One 8: e80292, 2013

31. Dellinger MT, Meadows SM, Wynne K, Cleaver O and Brekken RA: Vascular endothelial growth factor receptor-2 promotes the development of the lymphatic vasculature. PLoS One 8: e74686, 2013.

32. Fanoni D, Tavecchio S, Recalcati S, Balice Y, Venegoni L, Fiorani R, Crosti C and Berti E: New monoclonal antibodies against B-cell antigens: Possible new strategies for diagnosis of primary cutaneous B-cell lymphomas. Immunol Lett 134: 157-160, 2011.

33. Ilie M, Khambata-Ford S, Copie-Bergman C, Huang L, Juco J, Hofman V and Hofman P: Use of the 22C3 anti-PD-L1 antibody to determine PD-L1 expression in multiple automated immunohistochemistry platforms. PLoS One 12: e0183023, 2017.

34. Li H and Pauza CD: CD25(+) Bcl6(low) T follicular helper cells provide help to maturing $\mathrm{B}$ cells in germinal centers of human tonsil. Eur J Immunol 45: 298-308, 2015.

35. Misawa Y, Misawa K, Kawasaki H, Imai A, Mochizuki D Ishikawa R, Endo S, Mima M, Kanazawa T, Iwashita T and Mineta $\mathrm{H}$ : Evaluation of epigenetic inactivation of vascular endothelial growth factor receptors in head and neck squamous cell carcinoma. Tumour Biol 39: $1010428317711657,2017$. 
36. Solinas C, Garaud S, De Silva P, Boisson A, Van den Eynden G, de Wind A, Risso P, Rodrigues Vitória J, Richard F, Migliori E, et al: Immune checkpoint molecules on tumor-infiltrating lymphocytes and their association with tertiary lymphoid structures in human breast cancer. Front Immunol 8: 1412, 2017.

37. Talay O, Shen $\mathrm{CH}$, Chen L and Chen J: B7-H1 (PD-L1) on $\mathrm{T}$ cells is required for T-cell-mediated conditioning of dendritic cell maturation. Proc Natl Acad Sci USA 106 2741-2746, 2009.

38. Nam-Cha SH, Roncador G, Sanchez-Verde L, Montes-Moreno S, Acevedo A, Domínguez-Franjo P and Piris MA: PD-1, a follicular T-cell marker useful for recognizing nodular lymphocyte-predominant Hodgkin lymphoma. Am J Surg Pathol 32: 1252-1257, 2008.

39. Harter PN, Bunz B, Dietz K, Hoffmann K, Meyermann R and Mittelbronn M: Spatio-temporal deleted in colorectal cancer (DCC) and netrin-1 expression in human foetal brain development. Neuropathol Appl Neurobiol 36: 623-635, 2010.

40. Sharma P, Callahan MK, Bono P, Kim J, Spiliopoulou P, Calvo E, Pillai RN, Ott PA, de Braud F, Morse M, et al: Nivolumab monotherapy in recurrent metastatic urothelial carcinoma (CheckMate 032): A multicentre, open-label, two-stage, multi-arm, phase $1 / 2$ trial. Lancet Oncol 17: 1590-1598, 2016.

41. Okazaki T and Honjo T: PD-1 and PD-1 ligands: From discovery to clinical application. Int Immunol 19: 813-824, 2007.

42. Cheng X, Dai H, Wan N, Moore Y, Vankayalapati R and Dai Z: Interaction of programmed death-1 and programmed death-1 ligand-1 contributes to testicular immune privilege. Transplantation 87: 1778-1786, 2009.

43. Wang LL, Li ZH, Hu XH, Muyayalo KP, Zhang YH and Liao AH The roles of the PD-1/PD-L1 pathway at immunologically privileged sites. Am J Reprod Immunol: doi: 10.1111/aji.12710.

44. Kaur G, Mital $P$ and Dufour JM: Testisimmune privilege-Assumptions versus facts. Anim Reprod 10: 3-15, 2013.

45. Zhao S, Zhu W, Xue S and Han D: Testicular defense systems: immune privilege and innate immunity. Cell Mol Immunol 11: 428-437, 2014

46. Fankhauser CD, Curioni-Fontecedro A, Allmann V, Beyer J, Tischler V, Sulser T, Moch H and Bode PK: Frequent PD-L1 expression in testicular germ cell tumors. Br J Cancer 113: 411-413, 2015.

47. Zhang Y, Kang S, Shen J, He J, Jiang L, Wang W, Guo Z, Peng G, Chen G, He J and Liang W: Prognostic significance of programmed cell death 1 (PD-1) or PD-1 ligand 1 (PD-L1) expression in epithelial-originated cancer: A meta-analysis. Medicine (Baltimore) 94: e515, 2015.

48. Bentas W, Beecken WD, Glienke W, Binder J and Schuldes H: Serum levels of basic fibroblast growth factor reflect disseminated disease in patients with testicular germ cell tumors. Urol Res 30: 390-393, 2003.
49. Adam M, Schmidt D, Wardelmann E, Wernert N and Albers P: Angiogenetic protooncogene ets-1 induced neovascularization is involved in the metastatic process of testicular germ cell tumors. Eur Urol 44: 329-336, 2003.

50. Subbiah V, Meric-Bernstam F, Mills GB, Shaw KR, Bailey AM, Rao P, Ward JF and Pagliaro LC: Next generation sequencing analysis of platinum refractory advanced germ cell tumor sensitive to Sunitinib (Sutent ${ }^{\circledR}$ ) a VEGFR2/PDGFR $\beta /$ c-kit/ FLT3/RET/CSF1R inhibitor in a phase II trial. J Hematol Oncol 7: 52, 2014.

51. Jones A, Fujiyama C, Turner K, Fuggle S, Cranston D, Turley H, Valtola R, Bicknell R and Harris AL: Angiogenesis and lymphangiogenesis in stage 1 germ cell tumours of the testis. BJU Int 86: 80-86, 2000

52. Sakai Y, Hoshino H, Kitazawa R and Kobayashi M: High endothelial venule-like vessels and lymphocyte recruitment in testicular seminoma. Andrology 2: 282-289, 2014.

53. Carbognin L, Pilotto S, Nortilli R, Brunelli M, Nottegar A, Sperduti I, Giannarelli D, Bria E and Tortora G: Predictive and prognostic role of tumor-infiltrating lymphocytes for early breast cancer according to disease subtypes: Sensitivity analysis of randomized trials in adjuvant and neoadjuvant setting. Oncologist 21: 283-291, 2016

54. Turksma AW, Coupé VM, Shamier MC, Lam KL, de Weger VA, Belien JA, van den Eertwegh AJ, Meijer GA, Meijer CJ and Hooijberg E: Extent and location of tumor-infiltrating lymphocytes in microsatellite-stable colon cancer predict outcome to adjuvant active specific immunotherapy. Clin Cancer Res 22: 346-356, 2016.

55. Yu X, Zhang Z, Wang Z, Wu P, Qiu F and Huang J: Prognostic and predictive value of tumor-infiltrating lymphocytes in breast cancer: A systematic review and meta-analysis. Clin Transl Oncol 18: 497-506, 2016.

56. Zeng DQ, Yu YF, Ou QY, Li XY,Zhong RZ, Xie CM and Hu QG: Prognostic and predictive value of tumor-infiltrating lymphocytes for clinical therapeutic research in patients with non-small cell lung cancer. Oncotarget 7: 13765-13781, 2016.

57. Coussens LM, Zitvogel L and Palucka AK: Neutralizing tumor-promoting chronic inflammation: A magic bullet? Science 339: 286-291, 2013

58. Jain RK: Normalization of tumor vasculature: An emerging concept in antiangiogenic therapy. Science 307: 58-62, 2005.

59. Schlom J: Therapeutic cancer vaccines: Current status and moving forward. J Natl Cancer Inst 104: 599-613, 2012.

This work is licensed under a Creative Commons Attribution-NonCommercial-NoDerivatives 4.0 International (CC BY-NC-ND 4.0) License. 